\title{
A study of candidosis: the role of fomites
}

\author{
S Rashid, M Collins, R J Kennedy
}

\begin{abstract}
This study investigates treatment failure and recurrences of vulvo-vaginal candidosis. It reviews the factors possibly associated with both. Patients attending a department of genitourinary medicine with recurrent candidosis $(N=186)$ were entered in the trial. The patients were investigated for evidence of candidosis from vagina, rectal wall and buccal mucosa and were given antifungal therapy. Prevention and reinfection via fomites was studied by means of a single blind parallel study comparing the effect of soaking undergarments in the amphoteric biocide Tego 103G with the effect of a placebo soak. General and possible contributory factors influencing treatment and failure and recurrences were considered. The success rate of miconazole therapy was typical of any imidazole therapy: $85 \cdot 4 \%$. There was no evidence that modern oral contraceptives played a role in candidosis. Oral nystan reduced the rectal wall carriage from $39 \cdot 2 \%$ to $23 \cdot 2 \%$. Oral yeast carriage rate in women was $37 \cdot 6 \%$. The recurrence rate over a six month period was $\mathbf{4 7 \cdot 4} \%$. The laboratory results of Tego soaking reduced the yeast carriage on panties from $85 \cdot 2 \%$ to $23 \cdot 4 \%$. However, no evidence was found in the trial results that panties were a significant source of reinfection.
\end{abstract}

\section{Introduction}

Vulvo-vaginal candidosis is an increasingly prevalent disease $^{1}$ which can cause great personal discomfort and distress over a protracted period of time. ${ }^{2}$ Symptomatology is any permutation and degree of vaginal discharge, dysuria, pruritis and dyspareunia. ${ }^{3}$ As regards signs, vaginitis appears more often than vulvitis and is usually the more marked when both are present. Complaints of discharge vary from the thick and white to the thin and clear.

Candidosis is a sub-mucus infection and so specimens for laboratory diagnosis are taken by firm

Department of Genito-Urinary Medicine, Sunderland District General Hospital

S Rashid, R J Kennedy

Formerly of Department of Microbiology, South Shields General Hospital (deceased)

M Collins swabbing of relevant surfaces rather than as samples of discharge. Of the methods of diagnosis (wet or dry specimens for microscopy and culture) culture is the most sensitive and specific.

Specific therapies give high cure rates. ${ }^{4}$ Recurrence is frequent with figures as high as $20 \%$ being commonly quoted. ${ }^{5}$ Several sources of re-infection have been suggested; auto-infection from the digestive tract $^{6-8}$; from the sexual partner ${ }^{9-11}$ and from fomites, particularly panties. ${ }^{12}{ }^{13} \mathrm{~A}$ wide range of predisposing factors has been proposed including contraceptives, ${ }^{14} 15$ antibiotics, ${ }^{14}{ }^{16}$ corticosteroids, pregnancy, thyroid dysfunction, iron deficiency and diabetes.

This study was planned following earlier work showing that conventional machine washing with detergents did not eliminate yeasts from panties and a demonstration that overnight soaking in the amphoteric biocide, Tego 103G (manufactured by $\mathrm{T}$ $H$ Goldschmidt Ltd) before routine washing effectively rids clothing of yeasts. ${ }^{13}$

Patients, materials and methods

One hundred and eighty six patients attending a genitourinary clinic in Sunderland and South Shields were selected. All were symptomatic and gave positive culture results for candida species. Patients with microscopic evidence only of candidosis or who had received anti-fungal therapy in the preceding two weeks were not included in the study. No asymptomatic patients who were culture positive were included in the trial. All patients gave their informed consent.

For the purpose of this study the following investigations were carried out:

A wet film and a Gram stained vaginal specimen were examined microscopically for the presence of yeast blastopores and/or hyphae.

Culture specimens from vaginal wall, rectal wall (usually faecally contaminated) and buccal mucosa were streaked on agar plates of Sabouraud's dextrose agar (oxide), supplemented with penicillin (20000 units/1) and streptomycin (30000/1), and incubated at $37^{\circ} \mathrm{C}$ for $2-3$ days.

The currently worn panties were obtained (a replacement being provided). Of 186 patients included in the trial only one declined to submit her panties for investigation. Three standard-sized portions of the gusset were imprinted on Sabouraud's medium for incubation, two after overnight soaking, washing and drying (vide infra). 
Candida albicans was identified by the use of the formation of germ tubes in human serum. Any germ tube negative yeasts were identified by use of the commercial carbon assimilation kits. API-20C and API-50CH kits (API-Biomerieux (UK) Ltd). Strain analysis was carried out on both the initial 186 patients and on the isolates from patients with recurrence. Strains were differentiated by colony morphology after three days growth at $37^{\circ} \mathrm{C}$ on Yeast Morphology Agar (Difco) supplemented with $0.022 \mathrm{~g} / 1$ of bromocresol green. Individual colonies were picked off and further differentiated using a combination of the resistogram method of $\mathrm{McC}$ reight and Warnock ${ }^{17}$ and the determination of minimum inhibitory concentration (MIC) to miconazole as described by Odds. ${ }^{18}$

A full blood count was ordered.

The urine was examined by naked eye and tested for sugar.

Curative and preventive measures were pursued simultaneously.

Curative measures were:

a. Gyno-Daktarin (miconazole) pessaries 1 bd for 7 days.

b. Gyno-Daktarin (miconazole) cream bd for 7 days. c. Nystan (nystatin) 500000 units orally qds for 7 days.

This lengthy therapeutic regime was found to be more effective in recurrent candidosis in the authors' experience and therefore was used in this trial.

Prevention of recurrence via fomites was designed as a single blind parallel study. Half of the patients, randomly assigned, used $1 \%$ Tego $103 \mathrm{G}$ (vide supra) as an overnight soak for all their owned panties prior to routine washing. The other half, acting as controls, used $0 \cdot 1 \%$ Teepol, a detergent previously shown not to reduce yeast recovery (unpublished data).

Patients were requested to re-attend for assessment, 2, 4, 12 and 26 weeks after commencement of treatment. At each visit their clinical condition was noted and specimens for culture obtained from vaginal wall, rectal wall and buccal mucosa. The panties worn at the four week visit were obtained (and replaced) for culture study as above. Treatment
Table 1 Culture findings at initial visit

\begin{tabular}{lcl}
\hline Source & Number & Percentage \\
\hline Vagina only & 83 & $44 \cdot 6$ \\
Vagina and rectum & 33 & $17 \cdot 7$ \\
Vagina and mouth & 30 & $16 \cdot 1$ \\
Vagina, rectum and mouth & 40 & $21 \cdot 5$ \\
Panties & 150 (of 176) & $85 \cdot 2$ \\
\hline
\end{tabular}

failure was defined as a positive culture after completion of therapy.

Recurrence was defined as a positive vaginal culture at any visit following a negative culture at week two.

Factors possibly involved in treatment failure and/ or recurrence were reviewed in detail.

Statistical studies were $2 \times 2$ contingency $\chi^{2}$ tests to compare groups. Yates correction was not used.

\section{Results}

Initial visit Immediate microscopy of vaginal specimens allowed treatment to commence immediately in almost all patients. By patients' accounts, compliance in therapy was of a high order. No side effects were reported. Table 1 shows that in addition to the mandatory 186 culture positive vaginal specimens, rectal wall cultures were positive in a total of $73(39.2 \%)$ and buccal mucosa carriage similarly identified in a total of 70 $(37.6 \%)$. Rectum and mouth harboured yeasts in $40(21 \cdot 5 \%)$.

Yeasts were isolated by culture from 150 $(85.2 \%)$ of 176 panties tested at the time of the initial visit.

Two similarly sized cuttings from each pair of panties were soaked overnight in either Tego or Teepol. After simulated washing and drying the cuttings were imprinted on Sabouraud's medium. The respective yeast recovery rates were $3(1 \cdot 7 \%)$ of 176 and $107(66.8 \%)$ of 176.

Table 2 shows the distribution of germ tube

Table 2 Identification of initial yeast isolates

\begin{tabular}{|c|c|c|c|c|c|}
\hline Species & $\begin{array}{l}\text { Germ tube } \\
\text { test }\end{array}$ & $\begin{array}{l}\text { Vagina } \\
(n=186)\end{array}$ & $\begin{array}{l}\text { Rectum } \\
(n=73)\end{array}$ & $\begin{array}{l}\text { Mouth } \\
(n=70)\end{array}$ & $\begin{array}{l}\text { Panties } \\
(n=150)\end{array}$ \\
\hline $\begin{array}{l}\text { Candida albicans } \\
\text { Candida glabrata } \\
\text { Candida tropicalis } \\
\text { Candida Krusei } \\
\text { Candida lusitaniae } \\
\text { Unidentified } \\
\text { Co-infection of } C \text { albicans } \\
\text { and } C \text { glabrata }\end{array}$ & $\begin{array}{l}\text { +ve } \\
\text { - ve } \\
\text { - ve } \\
\text { - ve } \\
\text { - ve } \\
\text { - ve } \\
\text { +ve } \\
\text { - ve }\end{array}$ & $\begin{array}{c}175(94 \cdot 1 \%) \\
5(2 \cdot 7 \%) \\
2(1 \cdot 1 \%) \\
1(0.5 \%) \\
1(0.5 \%) \\
0(0 \%) \\
2(1 \cdot 1 \%)\end{array}$ & $\begin{array}{l}64(87 \cdot 7 \%) \\
- \\
- \\
- \\
8(11 \cdot 0 \%) \\
1(1 \cdot 4 \%)\end{array}$ & $\begin{array}{l}60(85 \cdot 1 \%) \\
- \\
- \\
\bar{C}(12 \cdot 9 \%) \\
1(1.4 \%)\end{array}$ & $\begin{array}{l}140(93 \cdot 3 \%) \\
= \\
- \\
-8(5 \cdot 3 \%) \\
2(1.3 \%)\end{array}$ \\
\hline Totals & & 186 & 73 & 70 & 150 \\
\hline
\end{tabular}


Table 3 Post treatment follow-up and findings

\begin{tabular}{llll}
\hline Follow-up & $\begin{array}{l}\text { Number } \\
\text { attending }\end{array}$ & $\begin{array}{l}\text { Vaginal culture } \\
\text { positive }\end{array}$ & $\begin{array}{l}\text { Vaginal culture } \\
\text { negative }\end{array}$ \\
\hline At 2 weeks & 151 & $22(14 \cdot 6 \%)$ & $129(85 \cdot 4 \%)$ \\
At 4 weeks & 114 & $17(14.9 \%)$ & $97(85 \cdot 1 \%)$ \\
At 12 weeks & 86 & $20(23 \cdot 3 \%)$ & $66(76 \cdot 7 \%)$ \\
At 26 weeks & 57 & $18(31 \cdot 6 \%)$ & $39(68 \cdot 4 \%)$ \\
\hline
\end{tabular}

results. Where yeasts were cultured from the panties the germ tube results correspond with the results of the yeasts isolated from the vagina of that individual.

Of note is the recovery of Candida lusitaniae from the vagina of one patient. This species has not previously been reported as a cause of vulvovaginitis although it has been identified as an opportunistic pathogen. ${ }^{19}$

Follow-up Table 3 and fig 1 summarises the follow-up findings. Of 151 attending two weeks after commencing the treatment schedule, 129 $(85.4 \%)$ were smear and culture negative and declared cured. Rectal wall cultures were positive in $35(23.2 \%)$ and buccal mucosa cultures were positive in $52(34.4 \%)$. These percentages compared with the initial findings of 39.2 and 37.6 respectively. The findings at the second follow-up test revealed recurrence in $17(14.9 \%)$ of the 114 attending.

Of the 111 panties obtained and tested at this visit $26(23.4 \%)$ were culture positive. Of the 26 culture positive $16(31.4 \%)$ were from cases of recurrence and $10(16.7 \%)$ from those whose vaginal cultures were negative.

The results do not indicate presence of yeast on panties is associated with recurrence $\left(\chi^{2}=3 \cdot 73\right)$. However, of those patients who were vaginal culture positive, yeasts were recovered from $75.0 \%$ of panties. Of those patients who were not recurrences at this visit the yeast recovery was

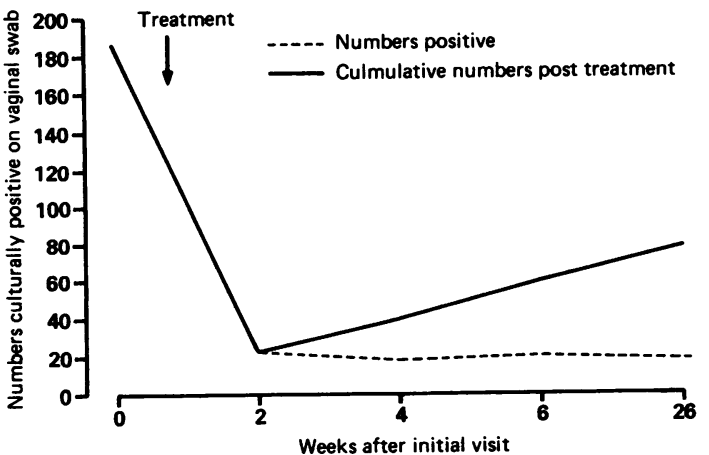

Fig 1 The reappearance of yeast in the vagina.

$6 \cdot 3 \%$. The $\chi$ being highly significant $\left(\chi^{2}=24 \cdot 89\right)$.

This result is most likely due to discharge from patients who had recurrence and it obscured analysis. Of the 48 initial vaginal isolates $12(25 \%)$ consisted of mixed strains as differentiated by the Resistogram method. In $23(48 \%)$ of the patients the original strain or in the case of mixed initial strains, the most prevalent original strain, was found in the recurrent vaginal isolate. In no case did any of the less prevalent strains re-appear in vaginal culture.

Factors influencing outcome The factors possibly influencing treatment failure and/or recurrence are dealt with as general and others; "possible contributory factors" (Group I) are compared with controls (Group II) in tables 4 and 5. $\chi^{2}$ analysis was used.

General factors Seven women were pregnant. Two were treatment failures. There was one recurrence. Routine haematological testing found three women with moderate iron deficiency. One was also a poorly-controlled diabetic. She was a treatment failure. One patient who was anaemic,

Table 4 Statistical analysis of factors which could influence treatment failure rate

\begin{tabular}{|c|c|c|c|c|}
\hline Group I & Group II & $\begin{array}{l}\text { Percentage of } \\
\text { treatment failures } \\
\text { in Group I }\end{array}$ & $\begin{array}{l}\text { Percentage of } \\
\text { treatment failures } \\
\text { in Group II }\end{array}$ & $\chi^{2}$ \\
\hline $\begin{array}{l}\text { Previous history of candidosis } \\
\text { History of candidosis in past year } \\
\text { Oral contraceptive user } \\
\text { Recent history of antibiotics } \\
\text { Patients aged } 25 \text { and under } \\
\text { History of oral sex } \\
\text { Patients with dentures } \\
\text { Patients who bathed less frequently } \\
\text { Patients wearing nylon panties } \\
\text { Patients who did not iron panties after washing } \\
\text { Patients using biocide soak (Tego) } \\
\text { Patients carrying yeasts in mouth and/or rectum }\end{array}$ & $\begin{array}{l}\text { No previous history of candidosis } \\
\text { No history of candidosis in past year } \\
\text { Other contraceptives/none } \\
\text { No history of antibiotics } \\
\text { Patients aged over } 25 \\
\text { No history of oral sex } \\
\text { Patients without dentures } \\
\text { Patients who bathed at least daily } \\
\text { Patients wearing cotton panties } \\
\text { Patients who ironed panties after washing } \\
\text { Patients using placebo soak (Teepol) } \\
\text { No yeasts found in other sites }\end{array}$ & $\begin{array}{l}14 / 84(16 \cdot 7 \%) \\
13 / 69(18 \cdot 8 \%) \\
11 / 80(13 \cdot 8 \%) \\
6 / 39(15 \cdot 4 \%) \\
14 / 109(12 \cdot 8 \%) \\
12 / 98(12 \cdot 2 \%) \\
0 / 10(0 \%) \\
13 / 75(17 \cdot 3 \%) \\
7 / 39(17 \cdot 9 \%) \\
19 / 115(16 \cdot 5 \%) \\
12 / 74(16 \cdot 2 \%) \\
10 / 68(14 \cdot 7 \%)\end{array}$ & $\begin{array}{l}8 / 60(13 \cdot 3 \%) \\
9 / 82(11 \cdot 0 \%) \\
10 / 69(14.5 \%) \\
15 / 101(14.9 \%) \\
8 / 42(19 \cdot 0 \%) \\
10 / 53(18.9 \%) \\
22 / 140(15 \cdot 7 \%) \\
9 / 76(11 \cdot 8 \%) \\
15 / 112(13 \cdot 4 \%) \\
2 / 23(8 \cdot 6 \%) \\
10 / 77(13.0 \%) \\
12 / 85(14.5 \%)\end{array}$ & $\begin{array}{l}0.30 \\
1.86 \\
0.02 \\
0.01 \\
0.99 \\
1.21 \\
1.84 \\
0.91 \\
0 \cdot 48 \\
0 \cdot 19 \\
0.32 \\
0.002\end{array}$ \\
\hline
\end{tabular}

All $\chi^{2}$ results are not statistically significant at the $5 \%$ level. 
Table 5 Statistical analysis of factors which could influence recurrence rate

\begin{tabular}{|c|c|c|c|c|}
\hline Group I & Group II & $\begin{array}{l}\text { Percentage of } \\
\text { recurrences } \\
\text { in Group I }\end{array}$ & $\begin{array}{l}\text { Percentage of } \\
\text { recurrences } \\
\text { in Group II }\end{array}$ & $\chi^{2}$ \\
\hline $\begin{array}{l}\text { Previous history of candidosis } \\
\text { History of candidosis in past year } \\
\text { Oral contraceptive user } \\
\text { Recent history of antibiotics } \\
\text { Patients aged } 25 \text { and over } \\
\text { History of oral sex } \\
\text { Patients with dentures } \\
\text { Patients who bathed less frequently } \\
\text { Patients wearing nylon panties } \\
\text { Patients who did not iron panties after washing } \\
\text { Patients using biocide soak (Tego) } \\
\text { Patients carrying yeasts in mouth and/or rectum }\end{array}$ & $\begin{array}{l}\text { No previous history of candidosis } \\
\text { No history of candidosis in past year } \\
\text { Other contraceptives/none } \\
\text { No history of antibiotics } \\
\text { Patients aged under } 25 \\
\text { No history of oral sex } \\
\text { Patients without dentures } \\
\text { Patients who bathed at least daily } \\
\text { Patients wearing cotton panties } \\
\text { Patients who ironed panties after washing } \\
\text { Patients using placebo soak (Teepol) } \\
\text { No yeasts found in other sites }\end{array}$ & $\begin{array}{c}31 / 62(50 \cdot 0 \%) \\
28 / 50(56 \cdot 0 \%) \\
31 / 60(51 \cdot 7 \%) \\
14 / 29(48 \cdot 3 \%) \\
38 / 84(45 \cdot 2 \%) \\
42 / 80(52 \cdot 5 \%) \\
4 / 9(44.4 \%) \\
25 / 55(45 \cdot 5 \%) \\
11 / 29(37 \cdot 9 \%) \\
39 / 84(46 \cdot 4 \%) \\
28 / 54(51 \cdot 9 \%) \\
31 / 62(50 \cdot 0 \%)\end{array}$ & $\begin{array}{l}19 / 47(40 \cdot 4 \%) \\
27 / 66(40 \cdot 9 \%) \\
24 / 55(43 \cdot 6 \%) \\
40 / 78(51 \cdot 3 \%) \\
17 / 32(53 \cdot 1 \%) \\
13 / 36(36 \cdot 1 \%) \\
51 / 107(47 \cdot 7 \%) \\
30 / 60(50 \cdot 0 \%) \\
44 / 87(50 \cdot 6 \%) \\
12 / 20(60.6 \%) \\
27 / 62(43.5 \%) \\
24 / 54(44 \cdot 4 \%)\end{array}$ & $\begin{array}{l}0.99 \\
2.60 \\
0.74 \\
0.08 \\
0.58 \\
2.67 \\
0.03 \\
0.24 \\
1.39 \\
1.19 \\
0.80 \\
0.36\end{array}$ \\
\hline
\end{tabular}

All $\chi^{2}$ results are not statistically significant at the $5 \%$ level.

responded to treatment. Vaginal culture for candida was negative at two and four weeks but was positive at 12 weeks. A third patient responded to treatment and remained negative (at 26 weeks).

Fifty three sexual partners were seen and 23 $(43 \%)$ were found to have some degree of balanoposthitis. Yeasts were cultured from nine patients with symptoms (39\%). No strain studies were done on men with proven candida. All 23 men were treated with a fungicide. One failed to respond. Three had a recurrence. Tables 4 and 5 list other factors.

History of candidosis Eighty six (46.2\%) of 186 patients had a history of candidosis. Some had had as many as 10 attacks. Even allowing for the uncontrolled diabetic who claimed 50-60 attacks, a history of candidosis played little or no part in treatment failure or recurrence.

Contraception Half the patients used oral contraceptives. The outcome in these did not differ from those using other forms of contraception or none at all.

Previous antibiotic therapy Antibiotics had recently been used by $50(30 \%)$ of the 186 study cases. They did not appear to influence treatment failure or recurrence rates.

Age Figure 2 shows the age distribution. It reflects the pattern of patients attending the Department of Genito-Urinary Medicine. There was no statistical difference in outcome between those over and those under 25 years of age.

Oral sex Two thirds $(65.1 \%)$ of the 184 questioned reported that they regularly practised cunnilingus and/or fellatio. There was no evidence that either or both influenced treatment failure. Numbers are too small to show any definite role for oral sex in recurrence.

Dentures The average age of the women was 23 years. Of the 184 questioned on this point, 13
$(7 \cdot 1 \%)$ had dentures. The small sample size gives no suggestion of dentures as an influencing factor. Personal hygiene Of the 184 questioned 99 $(53.8 \%)$ bathed or showered at least once per day. When compared with less frequent bathers, treatment failure and recurrence rates showed no significant differences.

Undergarments No less than $77 \cdot 2 \%$ of the patients claimed to wear cotton panties regularly rather than nylon. There was no difference in the treatment response rates of the two groups. Only $16.2 \%$ regularly ironed their cotton panties and this was of no statistical significance. Although Tego soaking in laboratory conditions proved reasonably effective it did not effect clinical recurrence rates.

Influence of digestive tract yeast findings Neither the initial presence nor the persistence of yeasts in the rectum or mouth appear to have influenced clearance or recurrence of vulvo-vaginal candidosis to any marked degree.

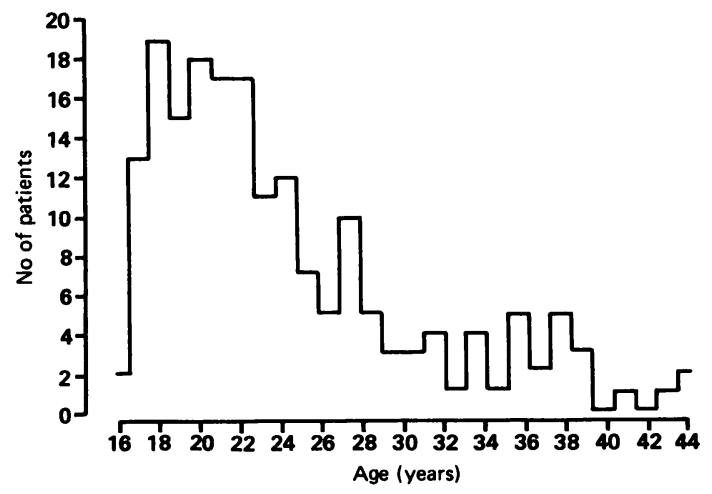

Fig 2 Age incidence of patients. 


\section{Discussion}

The treatment success rate was typical of miconazole therapy.$^{202}$ Only the iron deficient diabetic offered a clear cut reason for treatment failure. Other possibilities such as a past history of candidosis and being under 25 years of age, did not individually contribute to treatment failure.

As regards the preventive aims of therapy, oral nystatin reduced rectal wall yeast carriage from $39 \cdot 2 \%$ to $23 \cdot 2 \%$. These figures are well within the extremes of $17 \%$ to $75 \%$ found by others for rectal carriage. ${ }^{11416}$ There was no significant change in oral carriage. Our findings are similar to those of others.

The high preponderance of $C$ albicans in the three sites tested (table 2), together with the frequency of findings of $C$ glabrata, agree with the extensive study of Hurley. ${ }^{22}$ Other studies have shown $C$ albicans frequencies ranging from $48 \%$ to $98 \%$.

The total recurrence rate of $47 \cdot 4 \%$ compares with the extremes of zero to the comparable $47 \cdot 8 \%$ reported by others. ${ }^{23-25}$ Our long follow-up no doubt contributed.

As in other studies, we found no evidence that modern oral contraceptives played a role in candidosis. Our figures for pregnancy are too small for worthwhile analysis.

Other causes of recurrence we have found even less easily identifiable with precision. Of the consorts, one was a treatment failure and three had recurrence. Others were possibly symptomatic carriers. It has been shown in an unselected group of males that genital yeast carriage varies between $15 \%$ to $18 \% .{ }^{926}$ Male consorts of women with vaginal candidosis had a yeast carriage rate of $49 \%$. Per contra, Davidson ${ }^{26}$ found $80 \%$ of female consorts of men with genital yeasts to be culture positive. Together, these findings confirm sexual transmission between partners and that overt infection is more likely to be sexually acquired in men than in women.

Report of oral carriage of yeasts in men and women varies from $6 \%$ to $54 \%$. In this study the carriage rate in women was $37 \cdot 6 \%$. With twothirds of the partnerships practising oral sex, transfer of yeasts is possible by kissing, fellatio and cunnilingus. In spite of the inherent indirect and direct possibilities of vulvo-vaginitis, our findings suggest that oral sex played only a minor role, if any, in recurrence.

Our male studies suggest that one in three recurrences may be attributable to a male consort. In view of the small figures it may well be less. It has been suggested by Thin $e^{2} \mathrm{al}^{27}$ that one in three recurrences may be attributable to a male consort. If this is correct the two thirds of recurrences appear to be due to auto-infection. By themselves such factors as personal hygiene, wearing cotton panties, and in some cases always ironing them, had no measurable preventive value.

The laboratory results of Tego soaking, the reduction of rectal carriage due to oral nystatin and the reduction of pantie yeast carriage rate from $85.2 \%$ (150 of 176 ) to $23.4 \%$ (26 of 111 ) together gave hope of minimising the recurrence rate. Such hopes were unfulfilled. The importance of the lower digestive tract as a source of autoinfection is commonly cited. ${ }^{781128}$ Peri-anal contamination converting panties into fomites thus appeared to offer a focus for prevention. Why this approach failed is not clear. Poor compliance and a combination of factors are possibilities. A significant role for undergarment remains unproven.

We thank Northern Regional Health Authority for funding this project. We are grateful to Janssen Pharmaceuticals for providing the miconazole, $T$ $\mathrm{H}$ Goldschmidt for providing Tego 103G and Marks and Spencer for supplying panties and tights. We are indebted to Dr R S Morton for his advice and comments. We would also like to thank the staff of Genito-Urinary Medicine in Sunderland and South Shields for their help during the study and the secretaries for the preparation of the manuscript.

Address for correspondence. Dr S Rashid, Sunderland District General Hospital, Kayll Road, Sunderland SR4 7TP.

1 Morton RS, Rashid S. Candida vaginitis. Proc $R$ Soc Med 1977;70 suppl:3-6.

2 Oriel JD. Clinical overview of candidal vaginitis. Proc $R$ Soc Med 1977;70 suppl:7-9.

3 Adler MW, Belsey EM. The value of genital symptoms and signs in women. British Journal of Family Planning 1984;10:84-8.

4 Odds FC. Cure and relapse with antifungal therapy. Proc $R$ Soc Med 1977;70 suppl:24-7.

5 Spitzbart A. Schwieriekeiten bei der Behandlung der Vaginalmykose. Mykosen 1968;11:617.

6 Hilton AL, Warnock DW. Vaginal candidosis and the role of the digestive tract as a source of infection. Br J Obstet Gynaecol $1975 ; 82: 922-6$.

7 Odds FC. Genital candidosis. Clin Exp Dermatol 1982;7:345-54.

8 Miles MR, Olsen L, Rogers A. Recurrent vaginal candidiasis. $J A M A$ 1977;238:1836-7.

9 Rodin P, Kolator B. Carriage of yeasts on the penis. BMJ 1976;1:1123-4.

10 Odds FC, Abbott AB, Reed TAG, Willmott FE. Candida albicans strain types from the genitalia of patients with and without candida infection. Eur J Obstet Gynecol Reprod Biol 1983;15:37-43.

11 Horowitz BS, Edelstein SW, Lippman L. Sexual transmission of candida. Obstet Gynecol 1987;69:883-6. 
12 Hurley R. Inveterate vaginal thrush. Practitoner 1975;214: 753-8.

13 Rashid S, Collins M, Corner J, Morton RS. Survival of Candida albicans on fabric after laundering. $\mathrm{Br} J$ Venereal Dis 1984;60:277-80.

14 Wilmott FE. Genital yeasts in female patients attending a VD clinic. Br J Venereal Dis 1975;51:119-22.

15 Rosenburg MJ, Rojanapithayakorn W, Feldblum PJ, Higgins $J E$. Effect of the contraceptive sponge on chlamydial infection, gonorrhoea and candidiasis. JAMA 1987;257:2308-12.

16 Oriel JA, Waterworth PM. Effect of mycocycline and tetracycline on the vaginal yeast flora. J Clin Pathol 1975;28 403-6.

17 McCreight MC, Warnock DW. Enhanced differentiation of isolates of Candida albicans using a modified resistogram method. Mykosen 1982;25:589-98.

18 Odds FC. Laboratory evaluation of antifungal agents: a comparative study of five imidazole derivatives of clinical importance. J Antimicrob Chemother 1980;6:749-61.

19 Libertin CR, Wilson WR, Roberts GD. Candida lusitaniae-an opportunistic pathogen. Diagn Microbiol Infect Dis 1985;3: 69-71.

20 Balsdon MJ, Tobin JM. Recurrent vaginal candidosis: prospective study of effectiveness of maintenance miconazole treatment. Genitourin Med 1988;64:124-7.

21 Miller PI, Humphries M, Grassick K. A single-blind comparison of oral and intra-vaginal treatments in acute and recurrent vaginal candidosis in general practice. Pharmatherapeutica 1984;3:583-7.

22 Hurley R. Trends in candidal vaginitis. Proc $R$ Soc Med 1977;70 suppl:1-2.

23 Odds FC. Cure and relapse with antifungal therapy. Proc $R$ Soc Med 1977;70:24-8.

24 Wilmott FE. Candidiosis. Recent Advances in Sexually Transmitted Diseases. 2nd ed. Edinburgh: Churchill-Livingstone, 1981:217-28.

25 Warnock DW, Speller DCE, Milne JD, Hilton AL, Kershaw PI. Epidemiological investigation of patients with vulvo-vaginal candidosis. Br J Venereal Dis 1979;55:357-61.

26 Davidson F. Yeasts and circumcision in the male. Br J Venereal Dis 1979;53:121-3.

27 Thin RN, Leighton M, Dixon MJ. How often is genital yeast infection sexually transmitted. $B M J 1977 ; 2: 93-4$.

28 Odds FC. Candida and candidosis. Leicester: Leicester Univ Press, 1979:53-62.

Accepted for publication 14 October 1990 